\title{
THE VALUE OF A CORE RESEARCH MODULE IN THE MEDICAL CURRICULUM
}

\author{
Joshua Thomas, $M B C h B, B S c^{\text {a }}$, Emily Bligh, $M B C h B, B S c^{a}$, \\ Elisabeth Baggus, MBChB, BMedSci $i^{\mathrm{a}}$, and Joanne Thompson, \\ $P h D, M S c, B A^{\mathrm{b}}$
}

\section{ABSTRACT}

Introduction: Application of research methods to medical research is a key skill that students should acquire during medical school. This study aims to determine the extent to which a mandatory research module increases students' perceived knowledge and interest in research. This study also aims to determine what academic outputs have arisen from the module, that is, presentations and publications, and whether it leads to more outputs compared to research undertaken by students outside the curriculum. This latter aim of the study is not yet documented in the literature.

Method: Sheffield medical students were invited to complete a questionnaire on their thoughts of the research module, any academic outputs that arose from the module and any further research that they had undertaken outside the module. Ordinal regression analysis was used to assess for differences between groups' answers to the Likert scales.

Results: 101 students answered the questionnaire. $72.3 \%$ of students agreed that the module increased their knowledge of medical research, while fewer students agreed that it increased their interest in research and desire to undertake further research. More undergraduates than postgraduates agreed that the module increased their knowledge $(p=0.048)$. There were no differences between the type of research project undertaken and students' opinions of the module. Students gained more academic outputs, that is, journal submissions

\footnotetext{
a Sheffield Medical School, Faculty of Medicine, Dentistry and Health, The University of Sheffield

${ }^{\mathrm{b}}$ Academic Unit of Medical Education, The University of Sheffield
} 
and conference presentations, from research undertaken outside of the module.

Discussion: This research found that students' main benefit from the module was increased knowledge of medical research, in agreement with previous studies. Given the importance of publication, further research should be undertaken to determine why it is that extra-curricular research knowledge benefits students wanting to publish and how a mandatory module can facilitate publication.

Keywords: medical students, methodology, medical research, research module

Corresponding Author: Joshua Thomas, 30 Vaynor Road, Milford Haven, SA73 2NB

E-mail: joshualukethomas1@gmail.com

\section{INTRODUCTION}

In the United Kingdom, the General Medical Council (GMC) states in the document 'Outcomes for Graduates' that 'newly qualified doctors must be able to apply scientific method and approaches to medical research' (General Medical Council, 2018).

Medical students can get involved with research in a number of ways. For 22/38 (58\%) of UK medical schools (according to their respective curriculum maps), a core research module (CRM) is a compulsory component of the curriculum, as is the case with Sheffield Medical School. Some students can choose to take a year out from their medical training to undertake an intercalated degree; many of these degrees have a significant research component to the course. Additionally, students may choose to undertake a research project as an extra-curricular activity. However, there can be significant barriers to students when trying to pursue a research project outside the curriculum. One significant barrier faced by students is finding a supervisor willing to guide them through a project. One study found that $53 \%$ of medical students who responded to a questionnaire had approached a supervisor to enquire about undertaking research, with only 38\% subsequently undertaking an extra-curricular research project (Nikkar-Esfahani, Jamjoom, and Fitgerald, 2012). Therefore, for those students who do not intercalate or who are unable to take part 
in research as an extra-curricular activity, a CRM in the curriculum may be their only exposure to research.

Undertaking research is not only beneficial in increasing students' skills, but it may also lead to further academic opportunities. These opportunities may come in the form of publishing their research reports or presenting their results orally, or by poster, at conferences. However, it has been shown that very few students submit articles for publication, with one study showing that only $14 \%$ of 515 UK medical students had done so (Griffin and Hindocha, 2011). Despite this, two points are awarded to students for publications when they apply to the Foundation Programme (UK Foundation Programme, 2019). Additionally, further on in a medical career, publications and presentations are awarded points when applying for specialty training (IMT Recruitment).

The aim of this study was to investigate whether a CRM at medical school had an impact on students' perception of their knowledge of scientific research, research methodology and their interest in research, and to ascertain whether any further academic opportunities arose from the students' research projects, that is, publications and presentations. The study also aimed to assess for any differences between the type of research project, for example lab-based or clinical, and students' benefit from the module. Finally, students' research experiences outside of the module were determined with the aim of assessing if they led to more academic outputs, compared to the CRM, which is yet to be acknowledged in the literature.

\section{CONTEXT}

At Sheffield Medical School, the Research Attachment Module is undertaken at the beginning of second year and lasts for six weeks. The aims of the module are to allow students to select a research project that they are interested in from a catalogue of projects, to undertake research as part of a team and to produce a final report summarising their research findings, which could be considered for journal submissions. The expected outcomes following the module include students being able to demonstrate an understanding of research methodology, show an understanding of the ethical dilemmas facing 
research and produce a final report. Finally, it is expected that students will gain experience in presenting, both during the 'flash presentations' and any other additional presentations required of them during the attachment.

Prior to the attachment, students choose and rank their five top priority projects from a catalogue of over 100 . The projects include a variety of qualitative, quantitative, lab-based, clinical and other studies. The students are then allocated to one of their top five chosen projects randomly, with the aim of making allocations fair.

Before the start of the project, students receive a number of teaching sessions relating to research. The sessions include the importance of research in clinical practice, how to get the most out of the module, qualitative research overview, evidence reviews, molecular and cellular biology overview and an overview of research methods in health. The students then spend a session in an IT lab to learn about and practise advanced literature searching techniques.

At the end of the module, students are required to deliver a 'flash poster presentation' to their peers. The students are then assessed on the written report which they have produced. Finally, the students are required to submit a 500-word reflection based on their experience.

\section{METHOD}

Medical students in years two to five $(n=800)$ were invited to complete the questionnaire on the CRM using Google Forms. The questionnaire was advertised on the medical students' e-portal and also on the year groups' Facebook pages. It included 19 questions and consisted of binomial, ordinal Likert scale and free-text questions (Appendix 1).

\section{Statistical Methods}

The responses to the questionnaire were analysed using IBM SPSS software (version 26). Ordinal regression analysis was used to assess for any differences in answers to the Likert scales between different groups, for example, between undergraduates and postgraduates. A $p$-value of 0.05 was taken as the cut-off for statistical significance. 


\section{Ethical Approval}

The study was approved by The University of Sheffield Ethics Board.

\section{RESULTS}

\section{Student Demographics}

101 medical students responded to the questionnaire (Table 1). The responses consisted of medical students from all years, excluding firstyear students who had not yet taken the research module: 41 (40.6\%) second years, $30(29.7 \%)$ third years, 20 (19.8\%) fourth years, $4(4 \%)$ fifth years and $6(5.9 \%)$ intercalating students.

The students were asked to specify what type of student they were in terms of past experiences. 90 (89.1\%) were undergraduates, 11 $(10.9 \%)$ were postgraduates, $1(1.0 \%)$ was an international student, 9

Table 1. Results of student demographics and type of research project

\begin{tabular}{|l|l|}
\hline & Number of students $(\boldsymbol{N}=101)$ \\
\hline Year group & \\
\hline Second year & 41 \\
\hline Third year & 30 \\
\hline Fourth year & 20 \\
\hline Fifth year & 4 \\
\hline Intercalating & 6 \\
\hline Student status & \\
\hline Undergraduate & 90 \\
\hline Postgraduate & 11 \\
\hline International & 1 \\
\hline Mature student & 9 \\
\hline Previous gap year & 8 \\
\hline Research type & \\
\hline Lab-based & 35 \\
\hline Clinical & 35 \\
\hline Public health & 26 \\
\hline Other & 5 \\
\hline
\end{tabular}


THE VALUE OF A CORE RESEARCH MODULE IN THE MEDICAL

(8.9\%) were mature students (defined as students aged $21+$ on starting the medical course) and 8 (7.9\%) students had taken a gap year prior to starting medical school.

\section{Research Type}

$35(34.7 \%)$ students undertook a lab-based research project, 35 (34.7\%) students undertook a clinical research project, 26 (25.7\%) undertook a public health project and a further 5 students (5.0\%) undertook a project not well defined in one of these categories.

\section{Students' Perceived Educational Benefits from the Module}

$48.5 \%$ of students agreed that the CRM increased their interest in medical research (median 3.0 - neutral) (Figure 1). 72.3\% of students agreed that the CRM increased their knowledge of research methodology (median 4.0 - agree) (Figure 2), with only $12.9 \%$ of students disagreeing. 39.6\% of students agreed that the CRM increased their desire to undertake further research (median 3.0 - neutral) (Figure 3), while $35.7 \%$ of students disagreed.

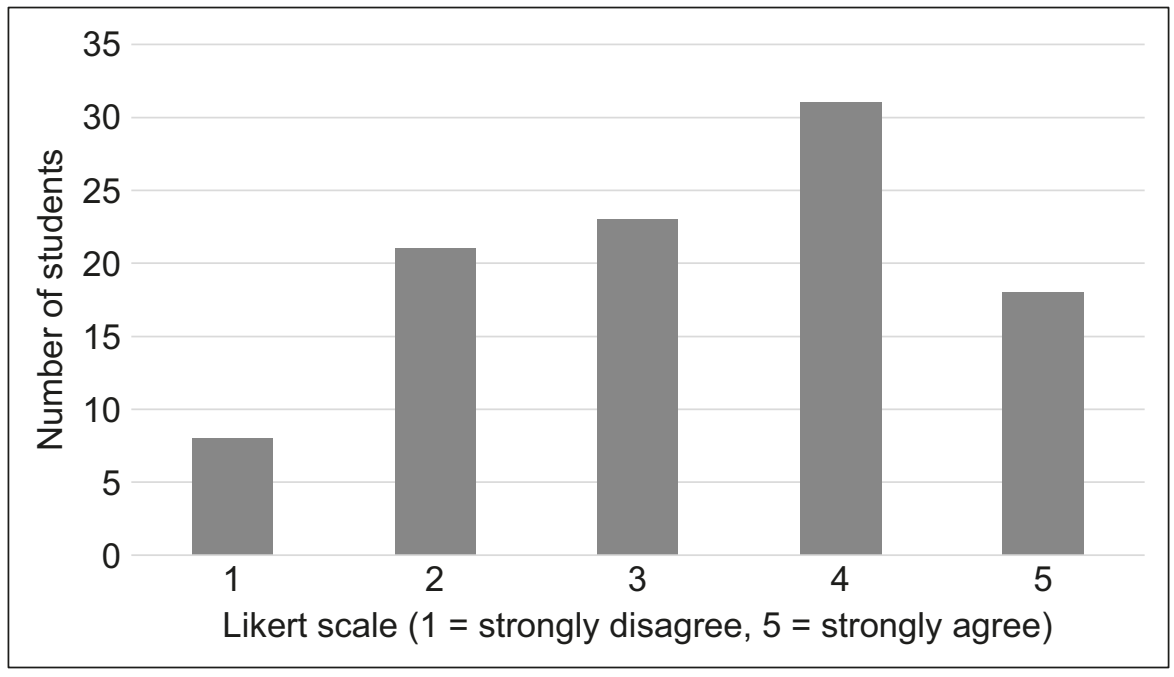

Figure 1. Likert scale demonstrating number of students agreeing with the phrase 'the research module increased my interest in medical research' 


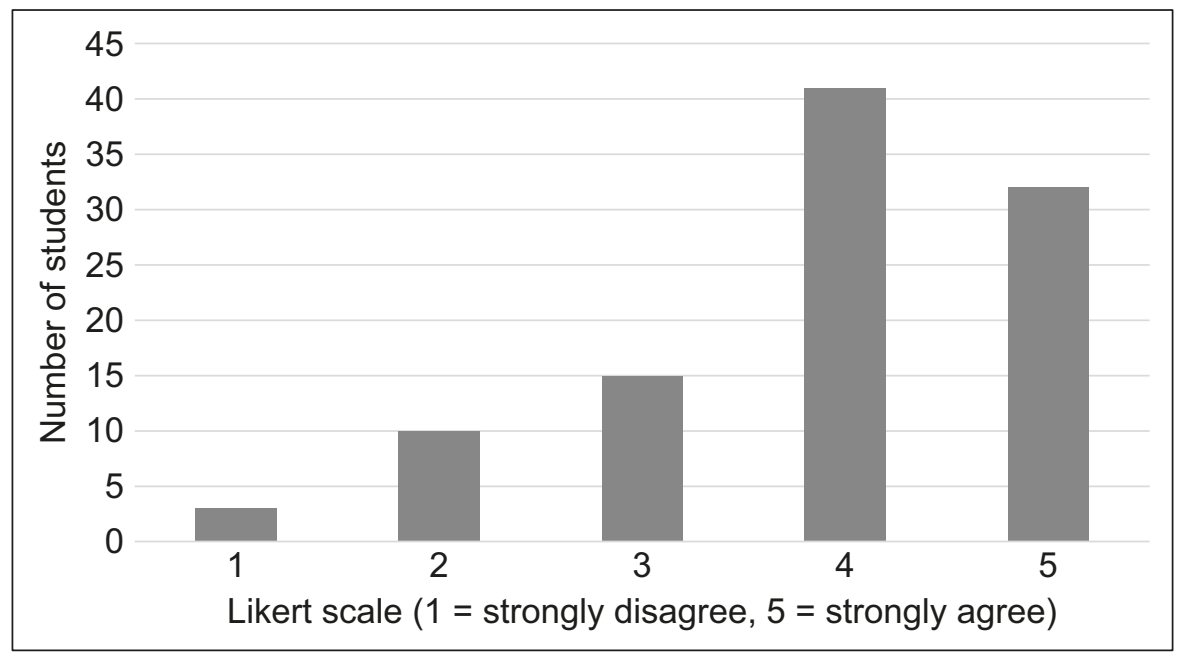

Figure 2. Likert scale demonstrating number of students agreeing with the phrase 'the research module increased my knowledge of research methodology'

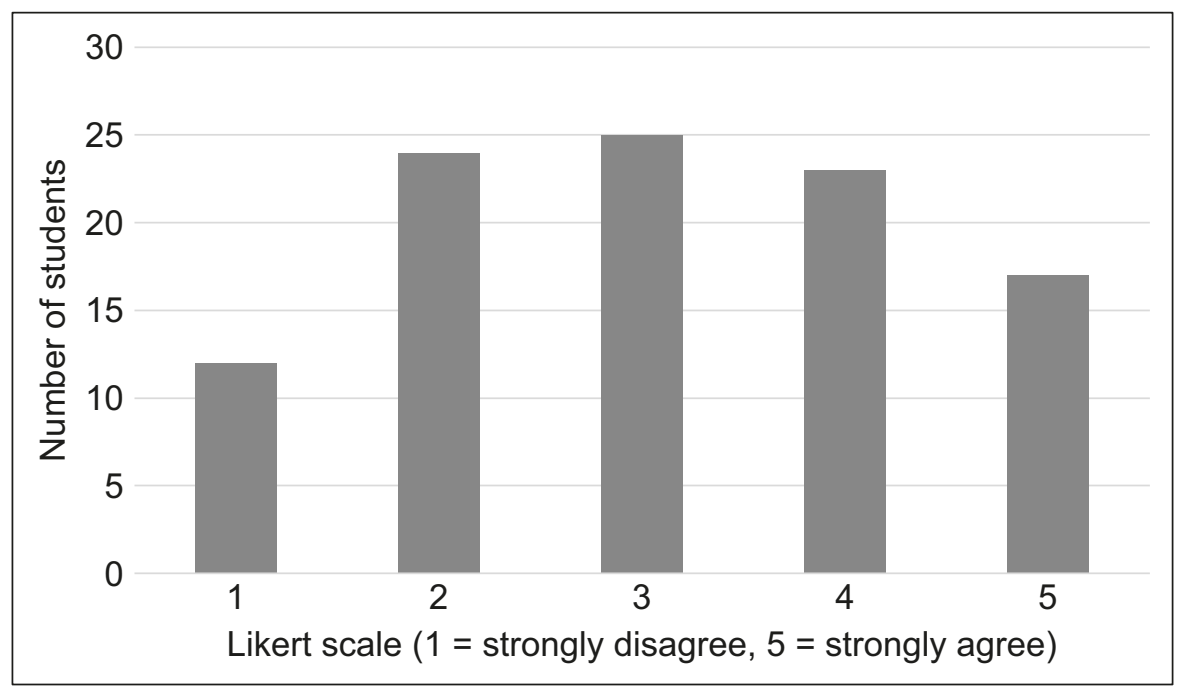

Figure 3. Likert scale demonstrating number of students agreeing with the phrase 'the research module increased my desire to undertake further research' 
There was no difference between undergraduates and postgraduates in agreement with increased interest or desire in medical research ( $p=$ 0.803 and $p=0.897$, respectively). However, there was a difference in agreement between undergraduates and postgraduates in increased knowledge of research methodology. More undergraduates than postgraduates agreed the module increased their knowledge of research methodology $(p=0.048)$.

Additionally, any differences between the type of research undertaken and the benefit students gained from the module were analysed. There was no significant difference between the research type undertaken and students' interest gained in, or students' desire to, undertake further medical research. Lab-based research resulted in students gaining an increased understanding in methodology compared to the other three groups; however, the differences were not statistically significant.

\section{Further Academic Opportunities Arising from the Research Module}

$19.8 \%$ of students went on to present their research module findings at an academic conference or meeting. Overall, $13.9 \%$ of students gave an oral presentation and $9.9 \%$ of students delivered a poster presentation. The students delivered their research findings at different sized conferences and meetings, with $5.0 \%$ presenting at a national conference and $4.0 \%$ at a regional conference. The majority of research presentations were undertaken locally, with $14.9 \%$ of students presenting at local meetings. It is important to note that some students presented their research findings more than once, and at conferences of differing sizes.

Of all students who participated in this study, only $4.0 \%$ published their research papers in academic PUBMED-ID-accredited journals.

\section{Research and Further Education Undertaken Following the Research Module}

$52.5 \%$ of students had undertaken an intercalated degree or wanted to undertake one in the future, $11.9 \%$ did not yet know if they wanted to 
study an additional degree. Of students who had completed an intercalated degree, $41.7 \%$ undertook a bachelor of science (BSc), $8.3 \%$ a master of science (MSc), 33.3\% a bachelor of medical science (BMedSci), $12.5 \%$ a master of public health (MPH) and $4.2 \%$ undertook a different degree.

With regard to extra-curricular research undertaken (besides intercalation), $27.7 \%$ of students had undertaken some form of research activity. No significant differences were found between students undertaking further extra-curricular research and those who had not and their agreement with the Likert scales, that is, increased interest, desire and knowledge of methodology.

Of those who had undertaken further research outside of the curriculum, $50 \%$ of students had presented their findings at a local conference, $50 \%$ at a national conference and $5.6 \%$ at an international conference. $33.3 \%$ published their findings in a PUBMED-IDaccredited academic journal.

\section{Academic Foundation Programme}

Students were questioned on whether they wanted to apply for the Academic Foundation Programme (AFP) following graduation; this programme contains a research or medical education component. $15.8 \%$ of students answered yes, $37.6 \%$ of students answered no and $46.5 \%$ had not yet decided.

\section{Students' Opinions on Further Teaching Topics}

Students were asked if they believe they would benefit from gaining teaching in the journal publication process and presentation skills during the module. $67.4 \%$ of students agreed that they would benefit from receiving teaching on the journal publication process and $68.4 \%$ of students agreed that they would benefit from teaching on presentation skills. This has been acknowledged and teaching is being considered for the module. Ideas for how to approach teaching on these topics include delivering sessions detailing the publication process, presentation tips and techniques and tips on manuscript preparation. 


\section{DISCUSSION}

This study addresses the GMC's aim for junior doctors to grasp an understanding of medical research, following this being mandated in their 'Outcomes for Graduates'. The document details a number of points which students must achieve prior to graduation and includes interpreting and communicating research results, critically appraising research information, formulating simple research questions and using evidence to inform care decisions (General Medical Council, 2018). Positively, this study found that students agreed the main benefit of this CRM was gaining knowledge in medical research. This is in agreement with previous research which has shown that similar modules have taught students skills in research methodology, in particular, learning to search for and critically appraise literature (Möllerand Shoshan, 2019). This suggests that incorporating a research module into medical school curricula is valuable when considering GMC's expectations for newly qualified doctors.

According to the results of this study, undergraduates gained more of an understanding of research methodology in comparison to postgraduate students. Completion of a dissertation has previously been found to improve students' ability to carry out research and critically appraise literature (Kuhnigk et al., 2010). Most postgraduates have completed a dissertation project prior to medical school, as well as possible research opportunities during their undergraduate studies; as a result, they could already be instilled with more confidence and feelings of self-efficacy when learning and practising research methodology. In order to grasp a better understanding of this disparity, an additional survey question assessing previous research experience could better determine the benefit of the project for students with varying previous practice and assess whether the CRM was the 'gateway' for some students into research.

Almost half of the participants found Sheffield's CRM to increase their interest in academia. Interestingly, in previous studies, certain project types such as basic science or epidemiological projects have been associated with better student ratings than clinical projects (Möllerand Shoshan, 2019); however, this was not the case in this study. This study is the first to show that a CRM does not increase 
students' scholarly outputs compared to other research experiences. Therefore, given the importance of publication, it would be interesting to investigate why those who seek further research experiences are more likely to gain publication and the role a CRM can play in increasing the publication rate in medical students. Previous and current studies are yet to identify the predictors of scholarly activity in medical students. A 2011 study found lack of opportunity to be the biggest barrier to publication (Griffin and Hindocha, 2011). However, one medical student's letter to the editor disagreed with this and believed student's motivation and initiative to be the barrier (Mabvuure, 2012). Studies have repeatedly found inability to find a project supervisor as a problem for medical students interested in pursuing further research (Siemens et al., 2010; Nicolaides et al., 2020). Perhaps this suggests that keener medical students who take the initiative to search for a supervisor are rewarded for their efforts. However, with this CRM this barrier is overcome, as students are paired with a supervisor for their project. Therefore, if this was indeed a barrier to scholarly activity, we would expect an increase in students producing research outputs. Despite this, only $4 \%$ of students achieved publication of their work from the Sheffield CRM. In comparison to a larger study of 392 students where approximately one-third of students published as a result of their mandatory module, this statistic is low (Möller and Shoshan, 2017). In line with students' response to wanting teaching on the publication process, we would like to introduce this, and determine whether this has an impact on the publication rate in future cohorts.

Medical students should be encouraged to practise research skills through methods aside from mandatory curricula, some of which include conferences, electives, intercalated degrees, student societies, audits and student study days (Nicolaides et al., 2020). A third of students who undertook research additional to the mandatory module gained a PUBMED-accredited paper. Of note, those who gained more research experience were also more likely to gain further outputs such as giving an oral/poster presentation. Publishing as a medical student has been associated with postgraduate success and also gives students more Educational Performance Measure (EPM) points allowing them a better chance of achieving their chosen foundation post or AFP (Mileder, 2014; UK Foundation Programme, 2019). 
The number of students in this study who reported their aims of pursuing an AFP was low and this could be a reason they did not want to do further research. This study also found that students' perceived benefits from the module did not have an impact on their involvement in further research. In line with this, a 2015 literature review identified a decline in clinicians' interest and engagement with research in Europe and North America over recent times (Chang and Ramnanan, 2015).

The students' motivation to involve themselves in further research should be investigated. Some disadvantages of extra-curricular research for medical students have been identified, which could discourage involvement. Problems faced include tremendous study burden, higher rates of burnout and correlation to depression in some students (Rached et al., 2018). Considering burnout has been linked to depression, it is important to ensure all students are aware of available support and that they do not overburden themselves with too much work (Fitzpatrick et al., 2019). By encouraging extra-curricular research in medical students, while ensuring awareness from project supervisors of barriers to publication, more outcomes and wellness could be achieved for future doctors.

Given the increase in interest seen in this study and others following mandatory research modules, we hope to see the introduction of such programmes at more medical schools alongside innovative teaching methods to help achieve the GMC goals and allow for more implementation of evidence-based medicine longer term.

\section{LIMITATIONS}

This study has limitations to be noted. A small proportion (4\%) of the survey participants were intercalating at the time of the study; these students tend to be involved in dissertations and further research building skills on their year away from medicine, with opportunity for publication. One reason for the small number of intercalating participants is many Sheffield students intercalate at alternative universities meaning they are less likely to keep updated with the Sheffield Facebook pages and medicine homepage, introducing an element of selection bias. This 
could have been avoided by emailing all members of the medical school, including intercalating students, to ensure an equal representation from all years. As a result, students currently involved in research may be underrepresented in the study and therefore results are slightly skewed. Additionally, a further limitation of this study is the low response rate of students in later years. This may have been because they do not remember their perceptions of the module or, with the final year students, being too busy due to joining the workforce early as a result of COVID-19. Ideally, a prospective study would better assess students' interest pre- and post-module as well as following up their research experience longer term. It is important to note that this study only assesses students' perceptions of the module. Therefore, an educational manipulation check before and after the module would better our understanding of the module's effectiveness and allow for comparison of research modules taught elsewhere. Finally, this study does not assess students' critical appraisal skills, which was an aim of the module and an essential part of evidence-based medicine. Questions exploring their perceived confidence in critical appraisal should be included.

\section{CONCLUSION}

This study has provided an insight into the impact of a CRM on students' perceptions of their knowledge of scientific research, research methodology and their interest in research while at medical school. A CRM was found to increase students perceived knowledge of research methodology, and interest in medical research. Students who conducted research independently, outside of the curriculum, were more likely to present their research and to achieve publication in PUBMED-indexed journals. This could potentially be addressed by providing teaching on the journal publication process and presentation skills as part of the curriculum, which students agreed would be beneficial to them. The type of research project conducted did not have an impact on success or outcomes. In conclusion, this study has clarified that there area range of benefits to a CRM; however, further research is needed to determine its role in encouraging publication and presenting findings. 


\section{ACKNOWLEDGEMENTS AND DISCLOSURE}

Funding: No authors have any relevant financial or nonfinancial interests to disclose.

Conflicts of interest: The authors declare that they have no competing interests.

Ethics approval: The study was approved by the University of Sheffield's ethics committee and the study was performed in accordance with the ethical standards as laid down in the 1964 Declaration of Helsinki.

Consent to participate: Informed consent was obtained from all individual participants included in the study.

Consent for publication: Participants consented for their anonymised data to be published.

Availability of data and material: The datasets generated during and/ or analysed during the current study are available from the corresponding author on reasonable request.

Code availability: Not applicable.

\section{REFERENCES}

Chang, Y. and Ramnanan, C.J., 2015. A review of literature on medical students and scholarly research. Academic Medicine, 90(8), pp. 1162-1173.

Fitzpatrick, O., Biesma, R., Conroy, R.M. and McGarvey, A., 2019. Prevalence and relationship between burnout and depression in our future doctors: a cross-sectional study in a cohort of preclinical and clinical medical students in Ireland. BMJ Open. 9:e023297.

General Medical Council, 2018. Outcomes for graduates. Available at: https://www.gmc-uk.org/-/media/documents/outcomes-for -graduates-a4-6_pdf-78952372.pdf

Griffin, M.F. and Hindocha, S., 2011. Publication practices of medical students at British Medical Schools: experience, attitudes and barriers to publish. Medical Teacher, 33(1), pp. 1-8.

Health Education England. 2021. Application scoring - IMT Recruitment [Online]. [Accessed 26 July 2021]. Available from: https://www.imtrecruitment.org.uk/recruitment-process/applying /application-scoring 
Kuhnigk, O., Böthern, A.M., Reimer, J., Schäfer, I., Biegler, A., Jueptner, M., Gelderblom, M. and Harendza, S., 2010. Benefits and pitfalls of scientific research during undergraduate medical education. GMS Zeitschrift fur medizinische Ausbildung, 27(5), pp. Doc72.

Mabvuure, N.T. 2012. Low medical student publishing rates: lack or opportunity or initiative? Medical Teacher, 34(3), pp. 254-255.

Mileder, L.P., 2014. Medical students and research: is there a current discrepancy between education and demands? GMS Zeitschrift fur medizinische Ausbildung, 31(2), pp. Doc15.

Möller, R. and Shoshan, M., 2017. Medical students' research productivity and career preferences: a 2-year prospective follow-up study. BMC Medical Education, 17(1), pp. 51.

Möller, R. and Shoshan, M., 2019. Does reality meet expectations? An analysis of medical students' expectations and perceived learning during mandatory research projects. BMC Medical Education, 19(1), pp. 93.

Nicolaides, M., Rallis, K., Eyskens, P.J., Andreou, A., Odejinmi, F., Papalois, A. and Sideris, M., 2020. A student initiative to improve exposure in research: dual benefit? Annals of Medicine and Surgery (London), 56, pp. 211-216.

Nikkar-Esfahani, A., Jamjoom, A.A.B. and Fitgerald, J.E.F., 2012. Extracurricular participation in research and audit by medical students: opportunities, obstacles, motivation and outcomes. Medical Teacher, 34(5), pp. 317-324.

Rached, G., Hobeika, C., Karam, E., Kourié, H.R. and Kattan, J., 2018. Urging medical students to publish: advantages, disadvantages and new challenges. Bull Cancer, 105(6), pp. 626-628.

Siemens, D.R., Punnen, S., Wong, J. and Kanji, N., 2010. A survey on the attitudes towards research in medical school. BMC Medical Education, 10, pp. 4.

UK Foundation Programme, 2019. UKFP 2020 applicant's handbook. Available at: https://www.foundationprogramme.nhs.uk/wp-content /uploads/sites/2/2019/10/UKFP-2020-Applicants-Handbook-.pdf 


\section{APPENDIX 1 - QUESTIONNAIRE}

1. What year group are you in?

2. What type of student are you? Tick any that apply
a. Undergraduate
b. Postgraduate
c. International
d. Mature
e. Gap Year

3. What type of research was your Research Attachment SSC?
a. Lab-based
b. Clinical
c. Public health
d. Other

4. Please give brief details of your Research Attachment SSC.

5. The Research Attachment SSC increased my interest in medical research $(1=$ strongly disagree, $5=$ strongly agree $)$

6. The Research Attachment SSC increased my knowledge of research methodology ( 1 = strongly disagree, $5=$ strongly agree $)$

7. The Research Attachment SSC increased my desire to undertake further research ( $1=$ strongly disagree, $5=$ strongly agree)

8. Did you get the opportunity to present your findings at any conferences/meetings?
a. Yes
b. No

9. If yes, please give details of the conference/meetings you presented at, and the type of presentation (oral/poster).

10. Did you get the chance to publish your findings in an academic journal?
a. Yes
b. No

11. If yes, please give details of the journal/s you published your findings in.

12. Intercalation?

a. I have intercalated/I am currently intercalating

b. I want to intercalate

c. I didn't intercalate/do not want to intercalate

d. I do not know if I want to intercalate 
13. If you have intercalated/currently intercalating. At what degree level was/is your course?
a. BSc
b. MSc
c. BMedSci
d. Other

14. Have you undertaken any further extra-curricular research (besides intercalation)?
a. Yes
b. No

15. If yes, please give details.

16. Has any of your further research experiences, intercalation or extracurricular, resulted in any of the following? Tick all that apply.
a. Oral/poster presentation at a local conference
b. Oral/poster presentation at a national conference
c. Oral/poster presentation at an international conference
d. Publication in an academic, PUBMED-ID-accredited journal

17. Are you wanting to apply for the Academic Foundation Programme?
a. Yes
b. No
c. Maybe
d. I don't know

18. I would benefit from receiving teaching on the journal publication process prior to the Research Attachment SSC (1 = strongly disagree, $5=$ strongly agree).

19. I would benefit from receiving teaching on presentation skills, both oral and poster, prior to the SSC ( 1 = strongly disagree, $5=$ strongly agree). 